\title{
Projeto Colaborativo Sem Fronteiras Ponte Atlântica Brasil e Portugal: Uma Experiência de Utilização do Laptop como Ferramenta Educacional
}

\author{
Walézia Lopes Vasconcelos de Souza ${ }^{1}$, Jaiane Ramos Barbosa ${ }^{1}$, José Aires de \\ Castro Filho ${ }^{1}$
}

1 Instituto UFC Virtual, Universidade Federal do Ceará (UFC). Campus do Pici, bloco $901-1^{\circ}$ andar, CEP: 60.455-760

\{walezia, jaiane, aires\}@virtual.ufc.br

\begin{abstract}
This study highlights the work of a collaborative project with support of the laptop as an educational tool. It originated from the Borderless Project: Atlantic Bridge Brazil and Portugal carried out in two public schools, one Brazilian and another Portuguese. The main objective of the project was the creation of digital materials collaboratively through interactions and cultural exchanges made between students. In order to analyze the results, data consisted of discussion forums, student's slides and field journals. In conclusion, the practices in question have contributed to building collaborative and meaningful learning.
\end{abstract}

Resumo. O presente estudo destaca resultados de um projeto colaborativo com suporte de laptop como ferramenta educacional. Surgiu da execução do Projeto Sem Fronteiras: Ponte Atlântica Brasil e Portugal, realizado em duas escolas públicas, uma brasileira e outra portuguesa. O objetivo principal do Projeto foi a criação de materiais digitais de forma colaborativa através das interações e trocas culturais realizadas entre os alunos. A fim de analisar os resultados, foram coletados dados dos fóruns de discussões e apresentações por meio de materiais digitais e registros em diários de campo. Conclui-se que, as práticas em questão, contribuíram para a construção de aprendizagem colaborativa e significativa.

\section{Introdução}

No mundo globalizado, a informação, a comunicação e a tecnologia caminham de forma acelerada. Nesse meio, a escola é uma instituição que se propõe a formar indivíduos com habilidades cognitivas que interpretem e deem significado a essas informações. A assertiva relaciona-se com a ideia de Montaigne apud Morin (2001, p. 21) de que "[...] mais vale uma cabeça bem-feita do que uma cabeça cheia". Nesse sentido o trabalho por projetos revela-se como uma nova opção pedagógica, já que é uma possibilidade quando se fala em romper barreiras e inovar as formas de ensinar e aprender.

De acordo com Almeida e Fonseca (2000) os projetos "criam possibilidades de ruptura por se colocarem como espaço corajoso [...] É uma forma de facilitar a atividade, a ação, a participação do aluno no seu processo de produzir fatos sociais, de trocar informações, enfim, de construir conhecimento" (p.14). O uso de projetos possibilita a autonomia do aluno no ato de aprender, corroborando para a sua formação integral, de forma que possa associar os conteúdos estudados em uma disciplina fazendo relação com outra e ainda utilize as variadas ferramentas disponíveis para a construção de sua aprendizagem. 
No cerne do trabalho por projetos, as Tecnologias Digitais da Informação e Comunicação (TDIC) são incorporadas para potencializar os processos de ensino e de aprendizagem. Um exemplo de tecnologia digital bastante presente hoje nas escolas são os computadores. Para Almeida e Fonseca (2000, p.18) com o uso dos computadores conseguimos chegar onde parecia impossível e podemos manipular o que é intangível, ver o que de tão pequeno é visível aos olhos. Podemos diminuir ou acelerar a velocidade dos acontecimentos, podemos recuar no tempo e espaço. Atentando para esses fatos o projeto aqui apresentado foi favorecido por essas possibilidades do uso do computador.

Esta pesquisa tem como objeto de estudo o Projeto Sem Fronteiras: Ponte Atlântica Brasil e Portugal (PSF) aliado ao uso das Tecnologias Digitais da Informação e Comunicação no contexto escolar, utilizando o laptop como ferramenta educacional. O referido projeto foi realizado no período de fevereiro a junho do ano de 2012, em duas escolas públicas de dois países distintos: Brasil e Portugal. Teve como objetivo principal proporcionar a troca de informação, cultura e gerar conhecimentos entre os alunos envolvidos, além de criar materiais digitais de forma colaborativa, fazendo com que a interação ocorrida entre eles tenha favorecido para a construção de uma aprendizagem para os envolvidos.

À guisa de orientação, o trabalho apresenta um relato de experiência buscando detalhar como se deu o desenrolar das atividades a partir da metodologia utilizada com o uso do laptop e suas ferramentas, bem como a importância desse tipo de trabalho para a promoção e o enriquecimento da aprendizagem dos participantes. Ademais, propõe uma reflexão baseada em teorias e nos dados empíricos coletados.

\subsection{Projetos Colaborativos e Tecnologias Digitais da Informação e Comunicação}

O trabalho por projetos colaborativos permite a construção em conjunto da aprendizagem, podendo facilitar as trocas de informações entre os participantes. De modo geral:

\footnotetext{
Implementar projetos significa oferecer a possibilidade de os alunos desenvolverem conhecimentos significativos para eles, que acabam aprendendo com o corpo todo porque entram por inteiro na grande aventura de descobrir, de inventar, tratando o conhecimento de modo integral e por inteiro. Aprender por projetos é transformar o processo da aprendizagem em algo meritório, que merece ser compartilhado [...] (ALMEIDA, 2000, p. 26).
}

Ao que se sabe, a aprendizagem ocorrida em grupos é motivo de curiosidade e de estudos há muito tempo. De acordo com Stahl, Koschmann, Suthers (2006, p. 3): "Mesmo nos anos 1960, antes do aparecimento dos computadores pessoais interconectados, havia uma investigação significativa sobre aprendizagem colaborativa realizada pelos pesquisadores de educação".

Atualmente, o termo colaboração está presente na maioria das discussões realizadas no meio educacional, principalmente, quando se fala em construção da aprendizagem partindo do envolvimento com projetos. Contudo, acredita-se que para se compreender como essa colaboração acontece deve-se saber o que ela significa:

A colaboração é um processo através do qual indivíduos negociam $e$ compartilham entendimentos relevantes à resolução do problema em questão. A colaboração é uma atividade coordenada e síncrona, resultado de uma tentativa contínua de construir e manter um entendimento compartilhado de 


\section{CBIE-LACLO 2015}

Anais dos Workshops do IV Congresso Brasileiro de Informática na Educação (CBIE 2015)

um problema (ROSCHELLE \& TEASLEY, 1995 apud STAHL, KOSCHMANN, SUTHERS, 2006, p. 3).

Portanto, quando se fala em colaboração, remete-se a ideia de trabalho em grupo, realização de tarefas conjuntas em prol de um objetivo comum e algo que ocorre de forma simultânea entre os integrantes. Entende-se que a colaboração é uma ação que objetiva resolver situações-problema de maneira compartilhada. No trabalho colaborativo, a distribuição de afazeres possibilita que cada membro se torne responsável para solucionar um problema. Na realização de projetos colaborativos, essa distribuição ocorre e pode ser vista de forma espontânea.

A partir da concepção de aprendizagem colaborativa apresentada defende-se que, na prática do trabalho por projetos colaborativos, a construção do aprendizado ocorre de modo coletivo, envolvendo e integrando os participantes para que eles não realizem as atividades de modo individual e isolado, mas que um contribua para a aprendizagem do outro.

Diante do exposto, considera-se que esse tipo de prática favorece a aprendizagem tanto individual quanto do grupo. Isso porque, para que os indivíduos realizem as atividades propostas e aprendam juntos, faz-se necessário que eles interajam entre si. A partir da interação é que os alunos conversam, discutem e buscam juntos encontrar soluções para as situações-problema em que são colocados durante o processo de construção do conhecimento em questão. A construção da aprendizagem compartilhada favorece ao aluno o desenvolvimento de habilidades, autonomia e criticidade, na medida em que o aluno é autor e tem papel ativo na construção de seu próprio conhecimento e dos colegas ao seu redor.

Para tanto, pensar em projetos colaborativos nos moldes atuais, oportuniza pensar no uso que se faz das TDIC como meio de apoio na realização desses projetos. As TDIC adentram na realização dos projetos colaborativos como um elemento facilitador do processo de aprendizado. O desenrolar de um projeto pode "[...] discutir sobre uma problemática de seu cotidiano ou de um assunto relacionado com os estudos de certa disciplina, envolvendo o uso de diferentes mídias" (PRADO, 2003, p. 6). No caso desse estudo destaca-se o uso do laptop como instrumento educacional que possibilita a construção de materiais digitais de forma colaborativa utilizando as ferramentas disponíveis no computador móvel.

Sabe-se que muitos estudos têm sido realizados com o intuito de discutir e aprofundar a aprendizagem em grupos apoiada pelas TDIC. Nesse contexto surge a Computer Supported Collaborative Learning (CSCL) que visa apresentar e investigar a aprendizagem colaborativa através do uso do computador e suas ferramentas. Ademais, discute como o uso das TDIC pode permitir o compartilhamento de dados, bem como informações com o intuito de gerir a aprendizagem e o trabalho a partir de grupos. Stahl, Koschmann e Suthers (2006) afirmam que o uso do computador como suporte favorece a aprendizagem colaborativa e que podemos nos apropriar das tecnologias como formas de favorecer essa aprendizagem. Asseveram, ainda, que, o ambiente computacional "pode analisar o estado da área de trabalho e as sequências de interação, e de acordo com estas informações, se reconfigurar ou oferecer dicas" (p. 13), isso porque esse meio é mutável, possibilitando a criação, a reformulação e a transformação do modo como se aprende. Contudo, destaca-se que para que se tenha sucesso na CSCL faz-se necessário uma nova postura pedagógica além do uso que se faz das ferramentas disponíveis. É necessária, além da inovação da prática pedagógica, uma mudança na 
concepção pedagógica existente, de tal modo que a aprendizagem através da colaboração pode ocorrer.

\section{Procedimentos Metodológicos}

O presente trabalho usou um método qualitativo. Esse tipo de método permite que os pesquisadores escolham e identifiquem as partes que se desejam aprofundar, selecionando os aspectos e informações que consideram relevantes ao seu estudo. Holsti apud Lüdke (1986, p. 39) autentica essa afirmação: "Quando o interesse do pesquisador é estudar o problema a partir da própria expressão dos indivíduos, ou seja, quando a linguagem dos sujeitos em forma escrita, como redações, dissertações, testes projetivos, diários pessoais, cartas etc". Inicialmente, foi realizada uma coleta de dados a partir das observações feitas e registros nos diários de campo, além da análise da participação dos alunos nos fóruns de discussão do Ambiente Colaborativo de Aprendizagem SÓCRATES ${ }^{1}$.

\subsection{Local e Participantes}

O projeto ocorreu simultaneamente em duas escolas públicas de realidades culturais distintas: uma localizada no município de Fortaleza no Brasil e a outra em Braga em Portugal. Teve início com o planejamento no mês de fevereiro de 2012 e foi efetivado no período de maio a junho do mesmo ano.

O projeto surgiu em virtude da participação das referidas escolas em programas do governo federal de seus países, que disponibilizou um laptop com internet para cada aluno. No caso do Brasil, o programa foi intitulado Um Computador por Aluno (UCA) ${ }^{2}$ e o laptop utilizado chamado de laptop educacional. No caso de Portugal o programa é chamado de Programa e.escolinhas ${ }^{3}$ com o uso do laptop "Magalhães", ambos os programas visam promover a inclusão digital implementando o uso de laptops no contexto escolar fazendo com que o uso da internet e de seus recursos favoreçam a aprendizagem dos alunos.

O PSF teve o intuito de promover a troca, a construção e o compartilhamento de materiais digitais através do desenvolvimento de práticas colaborativas entre os participantes, partindo da utilização dos laptops educacionais disponíveis, além de favorecer as trocas culturais, informações e experiências vivenciadas pelos envolvidos: alunos, professores e pesquisadoras.

O PSF envolveu um total de 45 alunos, sendo 25 da escola do Brasil e 20 de Portugal. No caso da escola de Fortaleza os participantes foram alunos do $9^{\circ}$ ano do Ensino Fundamental e da escola de Portugal os alunos do $10^{\circ}$ ano, que corresponde à séries equivalentes. Todos os alunos tinham idade entre 15 e 16 anos. O projeto envolveu um total de 4 professores: 3 professores do Brasil; sendo 1 professor de História Professor M e 1 professor de Geografia Professora C professor do Laboratório de Educacional de Informática LEI professora R e 1 de Portugal que leciona História da Cultura e das Artes Professor MR. O projeto também contou com a participação de 4

\footnotetext{
${ }^{1}$ http://www.virtual.ufc.br/socrates

${ }^{2}$ Disponível em http://uca-ce.blogspot.com.br/

${ }^{3}$ Disponível em http://eescola.pt/
} 
estudantes universitárias: sendo 2 graduandas em Pedagogia, 1 em Sistemas e Mídias Digitais e 1 mestranda em Educação. No total foram realizados 6 encontros presenciais. Com a frequência de uma vez por semana, com duração de uma ou duas aulas. Em dois desses encontros presenciais sucederam, também, dois encontros virtuais, esses realizados por meio de videoconferências no próprio LEI da escola.

A título de apreciação dessa pesquisa, os nomes dos alunos, professores e pesquisadores foram preservados, sendo aqui utilizadas letras como forma de identificação dos mesmos.

\subsection{Recursos materiais}

Os encontros virtuais aconteceram através da utilização das ferramentas disponíveis no SÓCRATES e por web conferências. O SÓCRATES disponibiliza o uso de ferramentas assíncronas, sendo elas: fórum, mensagem, portfólio, entre outros e foi escolhido porque a escola de Fortaleza já o utilizava devido à sua participação em outros projetos e por ser um AVA desenvolvido pela Universidade local.

As principais atividades realizadas foram fóruns de discussões no SÓCRATES e a criação de documentos e apresentações utilizando o Google Docs. O uso dessas ferramentas possibilita a criação de materiais digitais de forma colaborativa. Essas atividades foram pensadas visando oportunizar o manuseio das ferramentas sugeridas durante o projeto, além de possibilitar o registro das suas ações e contribuir para a construção da aprendizagem e experiência entre os participantes.

\section{Resultados e Discussão}

A partir do planejamento e desenvolvimento das atividades do projeto foram realizadas observações e considerações frutos de vivências que possibilitaram e contribuíram para o enriquecimento e construção do conhecimento dos envolvidos.

\subsection{O início do Projeto}

As ações, assim como os encontros, foram previamente planejadas de forma conjunta, entre os pesquisadores e os professores envolvidos, a fim de elaborar e conhecer a metodologia de trabalho, os instrumentais de observação, entre outros.

O planejamento aconteceu através de encontros presenciais e virtuais. Os encontros presenciais ocorreram no espaço da escola e os encontros virtuais através de web conferências realizadas no Hangout do Google+. Tinha como objetivo apresentar e discutir as ideias acerca da realização do projeto, dar início à construção do formato do mesmo. Nesse momento foram definidos: o cronograma, o AVA a ser utilizado, a duração das aulas, bem como o local para arquivamento das atividades.

\subsection{Materiais Digitais Colaborativos e Experiências}

Durante o projeto foram desenvolvidas diversas atividades, as quais foram realizadas de forma colaborativa pelos alunos. A Tabela 1 apresenta as atividades do projeto.

\section{Tabela 1: Atividades do Projeto}

\begin{tabular}{|l|l|}
\hline & $\begin{array}{l}\text { Apresentação do projeto feita pelo professor do LEI e pesquisadores; } \\
\mathbf{1}^{\mathbf{0}} \\
\text { semana } \\
\text { de Maio: }\end{array}$ \\
$\begin{array}{l}\text { Escolha do nome do projeto pelos alunos. Foi realizada uma votação com o objetivo de } \\
\text { escolher o nome oficial do projeto. Cada equipe do Brasil e de Portugal sugeriu nomes. } \\
\text { Sugestões dos pesquisadores: Descobertas Culturais entre Brasil e Portugal, Países Vizinhos: } \\
\text { um reencontro histórico entre Brasil e Portugal. Sugestão dos alunos do Brasil: Ponte }\end{array}$ \\
\hline
\end{tabular}




\begin{tabular}{|c|c|}
\hline & $\begin{array}{l}\text { Atlântica. Sugestão dos alunos de Portugal: Ponte Atlântica. Nome escolhido: Projeto Sem } \\
\text { Fronteiras: Ponte Atlântica Brasil e Portugal. } \\
\text { Criação de e-mails dos alunos no Gmail; Cadastro dos alunos no SOCRATES e explicação } \\
\text { sobre o manuseio do AVA; Participação no Fórum } 1 \text { intitulado "Apresentação", no qual os } \\
\text { participantes falaram sobre eles, o que gostavam de fazer nos horários livres e alguns aspectos } \\
\text { que os caracterizavam. Ao final do encontro, a maior parte dos alunos já havia feito suas } \\
\text { contribuições no fórum citado. } \\
\text { Atividade 1: Interação. Descrição: Para iniciar a atividade os alunos foram divididos em } \\
\text { grupos. Cada equipe ficou com um dos tópicos apresentados abaixo. A forma de divisão dos } \\
\text { tópicos (sorteio, escolha) foi decidida pelos alunos e orientada pelo professor. Cada equipe } \\
\text { ficou com um dos quatro tópicos e criou uma forma de responder a um questionamento. Em } \\
\text { seguida postaram o link da produção no Fórum } 2 \text { para discussão no encontro seguinte. }\end{array}$ \\
\hline $\begin{array}{l}2^{\circ} \\
\text { semana } \\
\text { de Maio }\end{array}$ & $\begin{array}{l}\text { O segundo encontro foi destinado à construção dos materiais/apresentações respondendo aos } \\
\text { questionamentos do encontro anterior. } \\
\text { Disponibilização dos links das apresentações no Fórum } 2 \text { do AVA. As apresentações foram } \\
\text { realizadas utilizando uma ferramenta colaborativa Google Docs. Nesse fórum, além dos alunos } \\
\text { postarem o link eles explicaram como se deu a sua postagem, além de comentarem as } \\
\text { postagens dos colegas. No fórum, foram criadas postagens com os nomes: Grupo } 1 \text { Brasil e } \\
\text { Grupo } 2 \text { Portugal e assim sucessivamente. }\end{array}$ \\
\hline $\begin{array}{l}3^{\circ} \\
\text { semana } \\
\text { de Maio: }\end{array}$ & $\begin{array}{l}\text { Primeiro contato em tempo real, de forma síncrona, entre os alunos; } 1^{\text {a }} \text { Web-conferênci } \\
\text { destinada a socialização e apresentação dos materiais construídos pelos alunos durante a } \\
\text { semana. Atividade } 2 \text { : O tema colonização. Descrição: Foram dadas as devidas orientações par } \\
\text { a construção da segunda atividade colaborativa: os alunos deveriam criar um material faland } \\
\text { da colonização do Brasil a partir dos brasileiros e portugueses. Na escola brasileira, os alunc } \\
\text { apresentariam a visão do colonizado e, na de Portugal, a visão do colonizador. }\end{array}$ \\
\hline $\begin{array}{l}4^{\circ} \\
\text { semana } \\
\text { de Maio: }\end{array}$ & $\begin{array}{l}2^{\text {a }} \text { Web-conferência: Apresentação das produções feitas no encontro anterior e discussão sobre } \\
\text { a percepção da colonização do Brasil a partir dos brasileiros e portugueses. Após as } \\
\text { apresentações, os alunos postaram os conteúdos produzidos no Fórum } 3 \text { do SÓCRATES. } \\
\text { Nesse encontro foi sugerida a construção de alguma apresentação artística, feita pelos alunos } \\
\text { de ambas as escolas, para ser apresentada durante a culminância do projeto. Ex: poesia, música } \\
\text { e dança. }\end{array}$ \\
\hline $\begin{array}{l}5^{\circ} \\
\text { semana } \\
\text { de Maio: }\end{array}$ & $\begin{array}{l}\text { Estava previsto para ocorrer o encontro de culminância do projeto e apresentação da } \\
\text { percepções dos alunos através de Web-conferência, mas foi adiada devido a problemas c } \\
\text { conectividade. Os alunos aproveitaram para aprimorar a apresentação de culminância d } \\
\text { projeto que ocorreu no encontro seguinte. }\end{array}$ \\
\hline $\begin{array}{l}\text { a } \\
\text { semana } \\
\text { de Junho }\end{array}$ & $\begin{array}{l}3^{\text {a }} \text { Web-conferência: culminância do projeto e apresentação das percepções dos aluno } \\
\text { Apresentações realizadas pelos alunos de ambas as escolas. Ao final das apresentações, } \\
\text { alunos discorreram sobre o que aprenderam com o projeto, utilização das tecnologias etc. } \\
\text { videoconferência proporcionou momento de socialização dos conhecimentos adquiridos a } \\
\text { longo do projeto entre os participantes dos dois países e aconteceu através de Google } \\
\text { Hangout. }\end{array}$ \\
\hline
\end{tabular}

Fonte: Elaboração Própria

Uma das principais atividades realizadas durante o projeto foi a participação dos alunos nos fóruns de discussões. Considera-se que as contribuições feitas nos fóruns foram enriquecedoras para os participantes, pois a partir das interações ocorridas, foi 


\section{CBIE-LACLO 2015}

Anais dos Workshops do IV Congresso Brasileiro de Informática na Educação (CBIE 2015)

possível o contato entre os alunos das duas escolas e dos professores e pesquisadores. A Tabela 2 apresenta algumas dessas participações ${ }^{4}$.

\section{Tabela 2: Participação no Fórum "Apresentação"}

Aluno BR (Aluno português): "Olá, eu sou a B, tenho 17 anos. Ando no curso de Artes Visuais, e gostava de ir para design moda. Gosto bastante de cinema, e tenho como preferencia terror/ficção. Gosto também muito de música e ouço de tudo um pouco. Penso que este projecto vai ser interessante, porque para além de conhecer-mos pessoas de países diferentes, ficamos a conhecer um pouco da sua cultura e dos seus hábitos." (Enviado em: 15/5/2012 as 18:40:34)

Aluno CS (Aluno brasileiro): "ola BR, gostaria de saber qual é o tipo de música que gosta mas de ouvir? tem algum estilo diferente ai em portugal diferente daqui do brasil ou não?" (Enviado em: 23/5/2012 as 13:42:12)

Fonte: Fórum de discussão "Apresentação"

Defende-se que as trocas de informações supracitadas promoveram novos conhecimentos, isso foi possível de perceber através das falas, diferenças e semelhanças quanto aos aspectos linguísticos, comportamentais e culturais entre os envolvidos. Nas discussões os assuntos abordados foram os mais diversos, entre eles: música, times de futebol, estação do ano, temperatura, cultura, poesia, tradições e costumes.

Outra atividade realizada colaborativamente pelos grupos foi a criação de materiais digitais utilizando a ferramenta Docs do Google. Após a elaboração as mesmas foram postadas no Fórum 2: "Interação - Nossas curiosidades e meu país é assim!", o que também culminou com os comentários nas postagens dos colegas, conforme mostrado na Tabela 3.

\section{Tabela 3: Criação de Material digital com ferramenta colaborativa no Google Docs}

Pergunta para o grupo 3 da escola brasileira: "Falem sobre um fato que vocês conhecem sobre Portugal?"

Resposta do grupo 3 da escola Brasileira:

"A ilha da madeira e dos açores tem um governo próprio diferente do de portugal, possuem um rio considerado muito importante que é $o$ rio tejo

Torre de belem é um dos monumentos mais expressivos da cidade de Lisboa, localiza-se na parte direita da margem do rio Tejo.

Pico na ilha de açores a região mais alta é a segunda maior ilha do árquepelago de açores,no Atlântico norte.

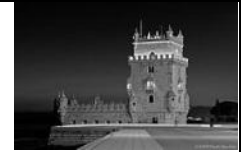

Santuário de Fátima a maior parte dos portugueses são católicos localizado na cova da Iria,freguesia de Fátima, é um dos mais importantes santuarios marianos do mundo.

Conhecido no Brasil Pastel de Belém os pasteis de nata,são um dos mais populares especialidades, da doçaria portuguesa. os portugueses fazem parte de uma cultura bem diversificada e bastante

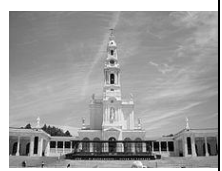

\footnotetext{
${ }^{4}$ Foi mantido a grafia original dos alunos.
} 
CBIE-LACLO 2015

Anais dos Workshops do IV Congresso Brasileiro de Informática na Educação (CBIE 2015)

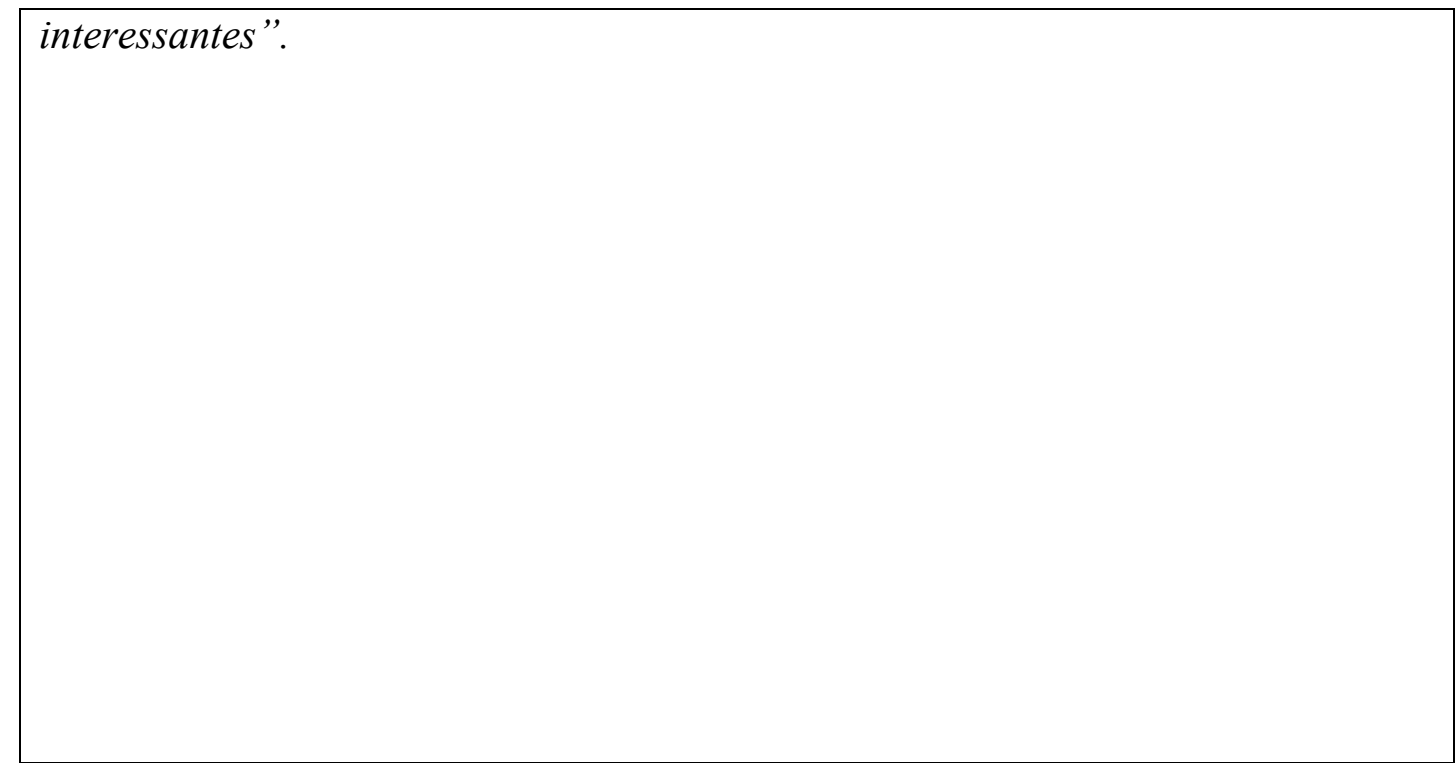

Fonte: Google Docs

A tabela 4 apresenta outro exemplo de material digital colaborativo.

Tabela 4: Material digital construído de forma colaborativa pelos alunos

$\begin{aligned} & \text { Pergunta para o grupo } 4 \text { da escola brasileira: “O que vocês acham que os } \\ & \text { portugueses deveriam saber sobre o Brasil?" }\end{aligned}$
$\begin{aligned} & \text { Resposta do grupo } 4 \text { da escola brasileira: } \\ & \text { "Musica Brasileira cantores: Ivete Sangalo >http://www.vagalume.com.br/ivete- } \\ & \text { sangalo/; Zeze di camargo \& Luciano > http://www.vagalume.com.br/zeze-di- }\end{aligned}$
$\begin{aligned} & \text { camargo-e-luciano/ Roberto carlos }>\text { http://www.vagalume.com.br/roberto-carlos/ } \\ & \text { Comidas Tipicas Brasileiras: Acarajé }>\underline{\text { http://tudogostoso.uol.com.br/receita/3158- }} \\ & \text { acaraje.html Feijoada >http://tudogostoso.uol.com.br/receita/2998-feijoada.html” }\end{aligned}$
Fonte: Google Docs

A partir das falas apresentadas nas tabelas, percebe-se que ocorreram momentos de interação e colaboração. O quesito interação foi perceptível porque tanto os alunos, quanto os pesquisadores e professores perguntaram e responderam, dialogaram entre si, de forma espontânea e com o objetivo de saber algo que, no momento, era de interesse comum. Quanto à colaboração, inicialmente era feita uma pergunta por um aluno e a partir dessa, os demais participantes se relacionavam para poder tirar as dúvidas existentes, quem sabia as respostas ia falando e quem quisesse perguntar mais também podia. Isso foi colaborativo porque eles juntos formularam e contribuíram para a construção do conhecimento do outro.

De tal modo, a seguir, comentaremos uma breve discussão acerca das contribuições que o referido projeto atrelado ao uso do laptop trouxe para os participantes.

\subsection{Discussões}

O planejamento realizado de forma conjunta possibilitou a troca de informações e de ideias, o que culminou com a concretização do projeto e o alcance dos objetivos propostos. Essa característica do planejamento foi fundamental para a criação e 
realização de um projeto que tem como característica marcante o trabalho colaborativo e o uso de tecnologia móvel como ferramenta de aprendizagem,

No início do projeto, muitos alunos apresentavam dificuldades em acessar o $e$ mail e, até mesmo, de encontrar na internet e no AVA o que procuravam. A partir da utilização das ferramentas disponibilizadas a cada encontro que, muitas vezes, tinham que realizar os procedimentos desde o início: procurar a página na internet, buscar as informações, imagens, links para que pudessem alcançar o seu objetivo, puderam compreender o funcionamento das ferramentas e suas possibilidades.

Mesmo diante das dificuldades encontradas, os alunos se interessaram em aprender e, principalmente, em fazer parte das atividades do projeto e desenvolveram habilidades através do uso e manuseio do laptop e de suas ferramentas. No momento em que faziam e buscavam por meio de tentativas solucionar o problema, como por exemplo, identificar qual a ferramenta é a mais indicada para realizar determinada tarefa, buscavam meios para chegar onde desejavam. Assim, estavam desenvolvendo sua autonomia. Dessa forma, confirmamos a ideia que:

\begin{abstract}
A pedagogia de projetos deve permitir que o aluno APRENDA-FAZENDO e reconheça a própria autoria naquilo que produz por meio de QUESTÕES DE INVESTIGAÇÃO que lhe impulsionam a CONTEXTUALIZAR CONCEITOS já conhecidos e DESCOBRIR outros que emergem durante o desenvolvimento do projeto. Nesta situação de aprendizagem, o aluno precisa selecionar informações significativas, tomar decisões, trabalhar em grupo, gerenciar confronto de idéias, enfim desenvolver COMPETÊNCIAS INTERPESSOAIS para aprender de forma colaborativa com seus pares (PRADO, 2003, p.7, grifo do autor).
\end{abstract}

Ainda com relação às contribuições trazidas, merecem destaque a comunicação e interação ocorridas durante a realização das videoconferências, visto que a maioria dos participantes ainda não tinha vivenciado esse tipo de experiência.

$\mathrm{Na}$ construção dos materiais digitais os alunos tinham o cuidado de selecionar imagens, buscar palavras para colocar no texto e na legenda. Também se observou que no processo de construção das respostas, os alunos brasileiros procuraram mostrar aos alunos de Portugal elementos que valorizavam a cultura do Brasil.

A partir da participação no projeto, os alunos tiveram a oportunidade de conhecer um pouco mais sobre a história de Portugal e sua relação histórica com o Brasil, além de utilizar o computador como ferramenta educacional e, com ele, possibilidades de aprender de uma forma dinâmica e atual.

\title{
4. Conclusões
}

Retomando a ideia inicial deste estudo, sobre a educação nos dias atuais e o uso das tecnologias digitais no processo de ensino e aprendizagem, conclui-se que é necessário refletir sobre as possíveis temáticas abordadas visando à implantação e $\mathrm{o}$ aprimoramento do uso das tecnologias móveis como suporte educacional.

Em resposta aos objetivos pretendidos, destaca-se que o PSF obteve resultados que contemplaram às expectativas traçadas inicialmente. Como visto, as principais atividades realizadas foram pensadas tendo em vista à oportunidade do manuseio das ferramentas disponíveis e permitidas pelo uso do laptop educacional, possibilitando o registro das ações ocorridas, contribuindo para a construção da aprendizagem e experiência dos participantes, além de ampliar os espaços de aprendizagem. Ademais, 


\section{CBIE-LACLO 2015}

Anais dos Workshops do IV Congresso Brasileiro de Informática na Educação (CBIE 2015)

as discussões realizadas no LEI, as trocas de informações ocorridas nos fóruns de discussão e videoconferências, o trabalho em grupos e a criação de documentos utilizando o Google Docs proporcionaram interação entre os participantes.

Dessa forma, entende-se que a aprendizagem colaborativa ocorrida com o suporte computacional, nesse caso o laptop, aconteceu, pois proporcionou a imersão do aluno à conectividade, mobilidade e construção coletiva de conhecimento. Ademais, contribuiu de forma significativa para os participantes proporcionando autonomia, ampliação do senso crítico, colaboração e significação da aprendizagem. Também possibilitou aprender de uma maneira diferente, conhecer formas, antes talvez inimagináveis de estudar e de colocar em prática novos aprendizados com os colegas através do uso das tecnologias na sua prática escolar. Nesse sentido, ressalta-se a importância do desenvolvimento de projetos e atividades aliadas ao uso de tecnologias móveis na educação.

\section{Referências}

Almeida, F. J. De; Fonseca Júnior, F. M. (2000) Proinfo: aprendendo com projetos. In: projetos e ambientes inovadores. Brasília. MEC.

Lükde, M.; André, M. E. D. A. (1986) Pesquisa em educação: abordagens qualitativas. São Paulo: epu.

Morin, Edgar. (2001) A cabeça bem-feita: repensar a reforma, repensar o pensamento. Tradução eloá jacobina. $3^{a}$ edição. Rio de janeiro: Bertrand Brasil.

Prado, M.E.B.B. (2003) Pedagogia de projetos. Série "pedagogia de projetos e integração de mídias" - Programa salto para o futuro, setembro.

Stahl, G; Koschmann, T; Suthers, D. (2006) Aprendizagem colaborativa com suporte computacional: uma perspectiva histórica. In: r. K. Sawyer (ed.), Cambridge handbook of the learning sciences. Cambridge, uk: Cambridge university press. pp. 409-426.

Instituto UFC Virtual. Sócrates. Sistema online para criação e gerenciamento de projetos colaborativos e comunidades virtuais de aprendizagem. Disponível em: $<$ http://www.virtual.ufc.br/socrates $>$. Acesso em: 10 de setembro 2012. 